\title{
Feeling Unequal: Social-Emotional Skills in the Reproduction of Social Class
}

\section{INTRODUCTION}

New studies from across the social sciences lend support to the influential idea that social-emotional skills are part of the agentic character of individuals (Heckman, Humphries, and Kautz 2014; Sampson 2016; The Brookings Institute 2014). They suggest that social-emotional skills have a causal effect on socio-economic attainment, net of social origins.

In the studies, social-emotional skills are measured by parental or teacher reports of observable behaviors in childhood, including self-control, externalizing behavior and internalizing behavior. ${ }^{1}$ Self-control describes behaviors such as persevering with a task, which indicate the capacity to regulate impulses (Duckworth 2011). Externalizing behaviors, such as aggression, indicate negative emotions directed outward toward others. Internalizing behaviors, such as tearfulness, indicate negative emotions directed inward toward the self. ${ }^{2}$

The existing studies find that, within families, those siblings with higher selfcontrol and lower levels of externalizing or internalizing behaviors are more likely to attain higher levels of education, income, and occupation in adulthood (Currie and Stabile 2006; Fletcher 2010; Moffitt et al. 2011). In addition, within groups of low-income children, and young men who did not graduate high-school, those with lower levels of externalizing behaviors and higher self-control went on to earn more (Heckman, Pinto, and Savelyev 2013; Heckman and Rubinstein 2001).

However, sociological theory suggests children learn ways to express and suppress their emotions according to social expectations and experiences that differ by 
social class (Hochschild 1979). If this account were true, social-emotional skills would not only predict who becomes socially mobile, but also help account for social immobility. While plausible and powerful, this hypothesis has not been adequately tested. Sociology has long considered different mediators of intergenerational class transmission. However, it continues to rely on models that either ignore, or simply condition on, alternative mediators, and so pose serious bias.

To address this limitation, I introduce a method developed in biostatistics, but not yet used in sociology: sequential g-estimation. This technique estimates a hypothetical counterfactual intergenerational class association where, at age ten, all children have average social-emotional skills regardless of class origin, but other known factors in intergenerational transmission are unchanged. For a nationally representative cohort sample recently reaching mid-adulthood, this counterfactual association is more than three percentage points smaller than the observed intergenerational class association. Fifteen percent of the association between class origins and destinations can therefore be said to work through social-emotional skills.

Not only has the existing literature not examined social-emotional skills as an independent mediator of class transmission, but in focusing on reported behaviors, it has not considered children's self-concept, or feelings of self-esteem and self-efficacy, as social-emotional skills. I argue self-concept can be considered a socially learnt, and socio-economically valuable skill, and find that it too mediates the intergenerational class association. In addition to behavioral self-control, self-concept is a mechanism by which social class is reproduced. 


\section{BACKGROUND}

\section{Social class origins and the development of social-emotional skills}

The idea that emotions are social, learnt skills is characteristically sociological. Most explicitly, Hochschild (1979) theorizes that socialization includes learning emotion management: how to express and suppress emotions in accordance with cultural feeling rules. This, she speculates, varies by social class origin. Children of higher class parents learn and practice ways to manage emotions that are expected and rewarded in higher class institutions. Meanwhile, children of lower class parents adopt styles of emotion management that might be adaptive to their lower class context, but prevent upward mobility. Consequently, "each class prepares its children to psychologically reproduce the class structure" (Hochschild 1979:551).

Socialization in emotion management could be considered part of what Lareau (2002) catalogs from her ethnography as higher class parents' concerted cultivation of their children. Higher-class parents, she argues, actively seek to develop skills in their children through reasoning with them and organized activities; social-emotional skills are likely to be particularly enhanced through such practices. Conversely, less preparation in emotion management could be seen as part of what Lareau calls lower class parents' natural growth style of parenting.

Children from lower social classes are more commonly reported to have low selfcontrol, and externalizing behaviors (Fletcher and Wolfe 2016; McLaughlin et al. 2011). These behaviors could be considered among the visible, embodied dispositions that signal and transmit class (Bourdieu 2000). Social class origins, however, could influence not only how feelings are expressed through behaviors, but also underlying ways to feel. 
The low status, power and resources experienced by people from lower classes is thought to generate negative emotions such as shame, anger and frustration more frequently. By contrast, the experience of being of a higher social class would generate more frequent feelings of pride, ease and control (DiMaggio 2012; Kemper 2006; Skeggs 2004). Such everyday feelings over time could crystalize in enduring emotionalcognitive, as well as behavioral, dispositions (Lizardo 2017; McLeod 2013; Simon 2014). Principally for children, these emotional-cognitions are about one's self. Self-concept, or what Cooley (1983) called self-feeling, has long been considered to be the internalization of social experience. Within self-concept, self-esteem develops through social comparison, stigma, and early (educational) successes and failures (Baumeister et al. 2003; McLeod 2013; Rosenberg and Pearlin 1978). Self-efficacy develops through the experience of personal control over one's life, and has been shown to increase with increased education (Bandura et al. 1996; Gecas 1982; Ross and Mirowsky 2012). For Lareau (2003), the primary consequence of class-differences in parenting is the sense of constraint it develops among children from lower classes - and the sense of entitlement that it develops among children from higher classes.

Those from lower classes tend to have lower self-esteem (Demo and SavinWilliams 1983; Rosenberg and Pearlin 1978), and lower self-efficacy (Kraus, Piff, and Keltner 2009; Ross and Mirowsky 2012; Wheaton 1980). These aspects of self-concept may underlie the behaviors that indicate social-emotional skills (Donnellan et al. 2005; Ross and Mirowsky 2012). Still, existing studies of social-emotional skills in status attainment overlook it. 


\section{Social-emotional skills and the attainment of social class destinations}

Emotions can be considered social skills not only because they are learnt, but also because they are of socio-economic value. A field experiment has shown that employers use signals of social-emotional skills to inform hiring processes at labor market entry; in fact they weight them more highly than signals of cognitive skills (Protsch and Solga 2015). If such signals are simply signs of class origins, social-emotional skills could be considered an arbitrary or exclusionary basis for selection into social class (Bourdieu and Passeron 1990). Psychology experiments find that people quickly and accurately assess others' social class from their emotional expression and non-verbal bodily behaviors (Kraus and Keltner 2009; Shariff, Tracy, and Markusoff 2012).

However, we should also expect social-emotional skills to enhance productivity if we understand economic activity as embedded in social and emotional relations (Berezin 2010; Zelizer 2012). Work often involves the production of positive feelings for customers, clients, and colleagues, or emotional labor (Wharton 2009). It follows that those better able to manage their emotions would command higher value and status in the labor market.

Social-emotional skills, considered as one latent factor, predict adult labor market outcomes (Cunha, Heckman, and Schennach 2010; Heckman, Stixrud, and Urzua 2006). Low self-control and externalizing behaviors remain associated with lower occupational prestige and educational attainment in sibling fixed-effect models that adjust even for unobserved shared family origin factors (Currie and Stabile 2006; Moffitt et al. 2011). Aspects of low self-control help explain why high-school dropouts who obtained a General Educational Development (GED) certificate went on earn less, despite having 
higher cognitive skills, than those who did not (Heckman and Rubinstein 2001). Reduced externalizing behaviors also help account for why low-income children receiving a randomized intensive early childhood intervention had higher adult earnings than those in the control group (Heckman et al. 2013).

Internalizing behaviors in adolescence affect the likelihood of high-school completion (and to a small degree, college completion) in sibling comparisons (Fletcher 2010). However, McLeod and colleagues find that unless combined with externalizing behaviors, internalizing behaviors are not associated with educational attainment (McLeod and Kaiser 2004; McLeod, Uemura, and Rohrman 2012). The lack of an independent association between internalizing behaviors and status attainment could indicate that it is only behaviors directed outward toward others (externalizing), or directly related to work productivity (self-control), that are consequential for class attainment.

Yet self-concept - an emotional-cognition rather than a behavior, but directed toward the self - might also influence class attainment. Self-efficacy, when combined with high educational expectations in adolescence, predicts higher earnings (Hitlin and Johnson 2015). Low self-efficacy also helps account for the discrepancy between stated intentions and behaviors among lower class young women (England 2015), and could be one reason why declarative personal cultural factors such as attitudes and aspirations generally fail to explain differences in status attainment (Kao and Thompson 2003; Lizardo 2017). In such ways, the subjective self-appraisal of one's worth and capabilities could have consequences for the attainment of objective class statuses. 


\section{Do social-emotional skills mediate the intergenerational transmission of class?}

Despite its power and plausibility, the hypothesis that social-emotional skills (whether behaviors or self-concept) act as a mechanism of class reproduction has not been adequately tested. Existing models of mediation either ignore, or simply condition on, alternative mediators, and so pose serious bias to estimates. In particular, while social-emotional and cognitive skills are generally considered separately (Hsin and Xie 2017; Mood, Jonsson, and Bihagen 2012), the two kinds of skills are highly correlated, and cognitive skills are known to affect class transmission (Hauser 2002). To test whether social-emotional skills meaningfully mediate class transmission, properly adjusting for other potentially confounding mediators, I use a method new to sociology: sequential gestimation.

\section{ANALYTICAL STRATEGY}

Are social-emotional skills a substantive mechanism in the intergenerational transmission of class? Analytically, this question considers origin class an exposure $\left(A_{i}\right)$, destination class an outcome $\left(Y_{i}\right)$, and social-emotional skills a mediator $\left(M_{i}\right)$. Answering the question without bias requires also considering intermediate covariates $\left(Z_{i}\right)$ : other mediators that potentially confound the role of social-emotional skills (Acharya, Blackwell, and Sen 2016; Robins 1989).

Structural Equation Models, including path analysis, remain the standard way to measure mediators. Sociology has developed and made good use of them in seeking to explain mechanisms of the intergenerational transmission of class (Bollen and Pearl 2013; Hout 2014). These models, however, either assume no intermediate covariates, or 
simply condition on them. Both omitting and conditioning on intermediate covariates can seriously bias estimates, either away from or toward zero. This can introduce selection bias and so potentially induce spurious associations, or block part of the pathway between the exposure and outcome (Acharya et al. 2016; Rosenbaum 1984). Sequential g-estimation addresses this intermediate variable bias by using a two-stage regression, and estimating what is called an average controlled direct effect (VanderWeele and Vansteelandt 2009; Vansteelandt and Joffe 2014).

The average controlled direct effect (ACDE) is the association between an exposure and an outcome when the value of a mediator is fixed at a particular level for all units in the data. In my case, the ACDE provides an intergenerational class correlation for a hypothetical counterfactual scenario in which all children, regardless of class origin, had mean social-emotional skills. The ACDE can be contrasted with an average total effect (ATE). In my case, this is the intergenerational class correlation when socialemotional skills take their observed values. The difference between the average total effect, and average controlled direct effect (ATE - ACDE) is a measure of the degree to which social-emotional skills mediate the association between class origin and destination. $^{4}$

An average total effect (ATE) can be decomposed into an average controlled direct effect (ACDE), an average natural indirect effect (ANIE) through the mediator and the interaction between the two, based on proof in VanderWeele (2015) and examples in Acharya, Blackwell and Sen (2016). ${ }^{5}$ In my case, the measure of the degree of mediation includes the interaction between the average controlled direct effect of class 
origin on destinations and the average natural indirect effect of class origin through its association with social-emotional skills. ${ }^{6}$

The average controlled direct effect, and therefore the degree of mediation, is estimated through two stages. First, we regress the outcome on the mediator, the baseline and the intermediate covariates altogether. This estimates the effect of the socialemotional skills on class destination, conditional on all other variables. Second, we use this estimate to demediate class destination - that is, subtract the effect of socialemotional skills from it. ${ }^{7}$ This demediated class destination is then regressed on class origins and baseline covariates only. The marginal effect of class origin in this second regression is the average controlled direct effect.

For the first stage, I use the following regression function for the expectation of class destination,

$$
E\left[Y_{i} \mid A_{i}, M_{i}, X_{i} Z_{i}\right]=a_{0}+a_{1} A_{i}+a_{2} M_{i}+X_{i} a_{3}+Z_{i} a_{4}+a_{5} M_{i} A_{i}
$$

where $X_{i}$ is a matrix of the baseline covariates, and $Z_{i}$ a matrix of the intermediate covariates, as detailed in the previous section. Note that $a_{1}$ is not the direct association between class origin and class attainment, because of the bias introduced by conditioning on the mediator and intermediate variables. The conditional effect of the mediator - a standard deviation decrease in social-emotional skills - on class destination is given by $a_{2}$.

The regression in equation (1) also includes the interaction between the effect of class origin $\left(A_{i}\right)$ and social-emotional skills $\left(M_{i}\right), a_{5} .{ }^{8}$ I use the estimates of both $a_{2}$ and $a_{5}$ to calculate the sample version of the demediation function for class destination:

$$
\hat{\gamma}\left(A_{i}, M_{i}, \hat{a}\right)=\hat{a}_{2} M_{i}+\hat{a}_{5} M_{i} A_{i}
$$


The second stage uses the demediation function in equation (2) to estimate the average controlled direct effect of origin class on destination. I demediate destination class, the outcome,

$$
\tilde{Y}_{i}=Y_{i}-\hat{a}_{2} M_{i}-\hat{a}_{5} M_{i}
$$

then regress this demediated outcome on the exposure and baseline covariates,

$$
E\left[\tilde{Y}_{i} \mid A_{i}, X_{i}\right]=\beta_{0}+\beta_{1} A_{i}+X_{i}^{T} \beta_{2}
$$

Variance and standard errors of the average controlled direct effect that account for the first-stage estimation are computed using nonparametric bootstrapping (Acharya et al. 2016). ${ }^{9}$ To obtain the estimate of the mediation of class transmission through socialemotional skills, I subtract the average controlled direct effect of class origin on class destination ( $\beta_{1}$ in equation 4$)$ from the average total effect, the intergenerational class association net only of the baseline covariates.

\section{DATA AND MEASURES}

Data. The data come from a nationally representative, longitudinal survey, the British Cohort Study (BCS). This study uniquely offers detailed prospective data on social-emotional skills from childhood, for a cohort recently reaching mid-adulthood. It sampled all children born in the United Kingdom in one week in 1970, with a $98 \%$ response rate $(\mathrm{N}=19,101)$ (Elliott and Shepherd 2006). Retaining all those with class destination information gives an analysis sample of $11,020 .^{10}$ Differential attrition is small and weights for attrition do little to improve estimates or their standard errors 
(Mostafa and Wiggins 2014). Still, to reduce bias driven by missing data, I use bootstrap expectation maximization to create, from the full sample and a model with over 50 socialdemographic variables over childhood, five imputed datasets (Honaker, King, and Blackwell 2011). ${ }^{11}$ Estimates and standard errors are combined across the five datasets based on Rubin's rules.

Social class $\left(A_{i}\right.$ and $\left.Y_{i}\right)$. Social class is measured by a six-group version of the Goldthorpe class schema. This standard measure reflects a hierarchy of labor market position, autonomy and security, from unskilled to professional occupations (Breen 2005; Erikson and Goldthorpe 2002). While offering a fuller picture of class attainment than education (Jackson et al. 2007), these macro occupational classes relate consistently over cohorts to education and wealth (Chan and Boliver 2013), and broader life conditions (Wodtke 2017).

Origin class $\left(A_{i}\right)$ is measured by the father's social class at the child's birth or at age five (with the mother's class substituted only in the few cases the father's is missing). This is appropriate for this cohort, when 30 per cent of mothers were housewives and for 90 percent of children the biological father was in the household. Destination class $\left(Y_{i}\right)$ is measured on the same scale at ages 29,34 and 38 . Taking the highest class over these multiple waves minimizes measurement error as well as missing data.

Social-emotional skills $\left(\boldsymbol{M}_{i}\right)$. Uniquely, the BCS offers a full range of prospective measures of child social-emotional skills for a recent cohort, developed and validated by psychologists. I use measures taken at age ten, the earliest age the full range of questions are asked - including of children themselves. ${ }^{12}$ 
Behaviors. Self-control is measured by a 9-item teacher assessment of the child's attention and perseverance using the Conners' Teacher's Hyperactivity Rating Scale and the Rutter Teacher Behavioral Scale B (Rutter 1967), a measure validated in contemporary settings (Daly et al. 2015). Externalizing and internalizing behaviors are each measured through 13 items, reported by the mother in a self-completion questionnaire (Elander and Rutter 1996; Goodman 1997). Externalizing behaviors include outbursts of temper, irritability, or being unable to settle. Internalizing behaviors include appearing fearful of new situations, eating and sleeping difficulties.

Self-concept. Self-esteem is a 13-item scale of a child's subjective self-worth, measured by their agreement with statements such as 'there are lots of things about myself I would like to change' (Lawrence 1981). Self-efficacy is a 13-item scale that captures the child's perceived locus of control, with statements such as 'it is not worth trying hard because things never work out anyway' (Nowicki and Strickland 1973). Low self-efficacy corresponds to an external, rather than internal, locus of control: the child believes outcomes are determined by factors that he or she cannot influence (Bandura 1986).

Descriptive statistics for all variables are provided in Table 1. Figure 1 illustrates the distribution in social-emotional skills by origin social class. Of all five socialemotional skill measures, subjective self-efficacy has the steepest social class gradient, followed by teacher-rated self-control.

Baseline covariates $\left(\boldsymbol{X}_{\boldsymbol{i}}\right)$. Baseline covariates are factors that potentially confound the effect of class origin on destination: child gender, race/ethnicity and disability. ${ }^{13} \mathrm{I}$ also 
conduct the analysis separately for males and females, because the extent to which, and ways in which, class is intergenerationally associated varies by gender (Kearney 2006; Schwenkenberg 2014). Minorities were not oversampled in the BCS, so I group nonwhites, and lack statistical power to model potential heterogeneity by race/ethnicity.

Intermediate covariates $\left(\boldsymbol{Z}_{\boldsymbol{i}}\right)$. Intermediate variables are those that could confound the effect of social-emotional skills. Cognitive skills and physical health are related to class origin, destination, and to social-emotional skills (Haas and Fosse 2008; Hauser 2002). For cognitive skills, I use the British Ability Scale, an unbiased assessment of literacy and numeracy taken at age 10 (Elliott, Murray, \& Pearson, 1978). For physical health, I use a mother's report of the degree to which any medical condition the child has affects daily life at home or school.

\section{RESULTS}

The sequential g-estimation method estimates a counterfactual intergenerational class association where social-emotional skills are set to means, and other intermediate variables are adjusted for: an average controlled direct effect (ACDE). Table 2 reports this, along with the intergenerational class association adjusting only for baseline covariates: an average total effect. The difference between the two -3.4 percentage points - is, as discussed in the analytical strategy section, a measure of the mediation of class transmission through social-emotional skills. That is, 15 percent of the intergenerational class association for this cohort is mediated by social-emotional skills. 
Separate mediation estimates for the behavioral and self-concept aspects of socialemotional skills are also reported in Table 2 . The degree to which the association between class origin and destination is mediated by the two measures of self-concept (8.1 percent) is not significantly different from that which is mediated by the three measures of behavior ( 9.8 percent). The mediation effect of both behaviors and self-concept is significant within the bootstrapped confidence intervals that account for the two-stage nature of the g-estimation, and imputed data. As Figure 2 visualizes, the mediation effect of behaviors and self-concept is largely additive: the combined effect is $85 \%$ of the sum of the two separate effects.

The output from the first-stage regression is reported in Table 3. It shows that conditional on each other, cognitive skills, and physical health, self-esteem and selfefficacy have significant, similar-sized associations with class destination. In this model, neither externalizing nor internalizing behaviors have a significant effect additional to that captured by teacher-rated self-control. ${ }^{14}$ Neither the interactions between parental class and social-emotional skills, nor those between the various social-emotional skills, are significant.

Gender differences. Separate estimates for males and females are reported in Table 2. The overall intergenerational class association is lower for females than for males (recall that father's occupation is used for origin class). For females, almost all of the mediation is through self-concept, with behaviors not by themselves statistically significant mediators with this halved sample size. For males, behaviors alone mediate 11.7 percent of the intergenerational class association. Still, slightly more of the male 
intergenerational class association is mediated through self-concept than through behaviors.

The role of cognitive skills. A legitimate question for the model is whether I have over-controlled for the effect of social-emotional skills by adjusting for cognitive skills at the same age. Although ten is the earliest age for which I have complete social-emotional skill measures, attention (an aspect of self-control) and externalizing behaviors at younger ages can predict later cognitive test scores (Duncan and Magnuson 2011; Turney and McLanahan 2015). I therefore repeat the analysis without including cognitive skill as an intermediate variable. As expected (and shown in appendix Table C3), this yields a larger estimate: social-emotional skills mediate 24 per cent of the intergenerational class association. This finding also shows the relevance of the adjustment for the covariance of cognitive and social-emotional skills, enabled by the sequential g-estimation method.

\section{DISCUSSION}

I hypothesized that social-emotional skills substantively mediate the intergenerational transmission of social class. The results of the sequential g-estimation show that if the association between class origins and social-emotional skills at age ten were broken, but if cognitive skills and health at the same age were unchanged, the intergenerational association would be over three percentage points, or 15 percent, lower. This mediation is substantial relative to the range of intergenerational class associations across rich nations, and over recent decades (Beller and Hout 2006; Buscha and Sturgis 2017). 
Sequential g-estimation is identified under the assumption of sequential unconfoundedness (Acharya et al.2016; Robins 1999). This assumption requires that there are no unmeasured confounders for the effect of exposure on the mediator, or for the effect of the mediator on the outcome, conditional on exposure. Without experimental data this assumption is unrealistic, and so I do not claim to establish a causal relationship, in either direction, between social class and social-emotional skills. As Duncan (1966) said of path analysis, sequential g-estimation is not a method to establish causes, but rather to address the problem of interpretation (Bollen and Pearl 2013). By addressing intermediate variable bias, the method still improves our ability to measure, and therefore theorize, social mechanisms of observed associations in population-level data. Despite the centrality of the intergenerational class association in sociology, our understanding of how its mechanisms act in the presence of other mechanisms remains limited (Hout 2014).

Without introducing an unwieldy number of counterfactuals, the model assumes that parental class has no effect on child social-emotional skills beyond that observed at age ten. This assumption likely yields a conservative estimate of the role of social-emotional skills in class transmission. Hsin and Xie (2017) show that parental factors become more predictive of a latent factor of social-emotional skills into adolescence, and Falci (2011) finds that class-origin gradients in self-concept steepen over childhood.

Measuring class origin by father's class also likely yields conservative estimates of social-emotional skills' mediation of class transmission (Beller 2009). Mothers play a disproportionate role in parenting, especially after a parental separation, and maternal characteristics are better than paternal characteristics in predicting children's social- 
emotional skills (Johnston, Schurer, and Shields 2013; McLanahan and Percheski 2008; Mensah and Kiernan 2010).

The mechanisms by which class reproduction occurs are dynamic and culturallyspecific (Bourdieu and Passeron 1990). This raises the question of generalizability. What we can say is that the United Kingdom and the United States are similar both in rates of social mobility (Beller and Hout 2006), and in gaps in social-emotional skills by parental class (Ermisch, Jäntti, and Smeeding 2012; Mazumder 2015). There is also evidence that the trend is for social-emotional skills to be increasingly graded by parental class (Maralani and Choi, forthcoming) - and that they are more important, at least relative to cognitive skills, in determining adult income (Deming 2015). We could therefore expect that the estimates here for the role of social-emotional skills in class reproduction will be underestimates for younger cohorts.

\section{Feeling Unequal}

Economics has recently drawn attention to the importance of what it calls "character" in socio-economic outcomes. It has persuasively identified net effects of the behavioral management of emotions in status attainment. Yet because social-emotional skills are significantly correlated between siblings, and between parents and children (Anger and Schnitzlein 2016; Mazumder 2015), these net effects capture a partial, and potentially selective, picture of their function in stratification at the societal-level.

Sociology has long recognized that various "non-cognitive" factors will influence status attainment, and help explain why some people are socially mobile (Farkas 2003; Jencks 1979; Sewell and Hauser 1974). However, sociologists have also long thought that 
differential socialization into emotion management would help explain why many others are socially immobile (Hochschild 1979). This analysis provides the first quantitative support for this idea. It shows that, even conditional on major mediators such as cognitive skill, social-emotional skills substantially mediate the intergenerational class association.

This paper also elaborates the theory of emotional management and class reproduction by considering self-concept as a social-emotional skill. Self-feelings, sociologists have claimed since Cooley and Mead, are a social product; a looking-glass that "reflects" class-based social experiences (Cooley 1983; Mead 1983; Yeung and Martin 2003). My analysis suggests that self-concept also "projects" class origins to affect class destinations. Consistent with McLeod and Kaiser (2004), I find that internalizing behaviors (those directed toward to self) are not associated with class attainment independent of externalizing behaviors (and, in my model, self-control). ${ }^{15}$ However, I find that internal emotional-cognitions directed toward to self - both selfesteem and self-efficacy - are so associated. Self-concept, as young as age ten, is not only graded by class origin, but predictive of class destination.

Integrating social-emotional skills into the literature on class stratification is a large project, which this article must stop short of. In particular, heterogeneity by gender and potentially by race/ethnicity demands further investigation. What the results presented here do show is a need to deepen the analysis of class reproduction to incorporate social-emotional skills - and to consider their emotional-cognitive, as well as behavioral, dimensions. Self-feelings demand attention not only as a 'hidden injury' of class inequality (Sennett and Cobb 1993), but also as an often-hidden mechanism that reproduces it. 


\section{ENDNOTES}

${ }^{1}$ Social-emotional skills can be considered a subset of non-cognitive skills, that is skills other than cognitive skills. I avoid the term 'non-cognitive' because few social-emotional skills do not involve thought or mental processes. Non-cognitive skills sometimes refers to personality traits, specifically the "big five" of Openness, Conscientiousness, Extroversion, Agreeableness and Neuroticism (Heckman et al. 2006). However, cognizant of theoretical and empirical critiques of this personality model (Boyle 2008; Savelyev 2014), I do not consider personality traits social-emotional skills.

${ }^{2}$ High levels of all these behaviors also indicate poor mental health. Low self-control has been used to indicate hyperactivity, externalizing behaviors conduct disorder, and internalizing behaviors anxiety and/or depression.

${ }^{3}$ Both emotional-cognitive and behavioral dispositions could be aspects of what Lizardo (2017) delineates as personal, non-declarative culture. Sociologists of culture, and of emotions, increasingly suggest that emotional and cognitive schemas, structures of feeling and thought, are mutually learnt and employed (Illouz, Gilon, and Shachak 2014; Lizardo 2017).

${ }^{4}$ A Directed Acyclic Graph (DAG) visualizing the analytical strategy is provided in Appendix Figure B1.

${ }^{5}$ Without assuming a constant interaction at the individual level, it is not possible to separate the natural indirect effect and the interaction between it and the controlled direct effect. However, even without the assumption, the indirect effect and interaction combined measure the role of the mediator in the association between exposure and outcome (Acharya et al. 2016). 
${ }^{6}$ This definition of a mediator is wider than that in Imai, Keele, and Yamamoto (2010), which considers causal mechanisms only in terms of indirect effects. It is however, consistent with VanderWeele's (2015) sufficient cause framework, which states that there can be variables that participate in the mechanism that are unaffected by treatment (Acharya et al. 2016).

7 'Demediation function' is terminology introduced by Acharya et al (2016); in biostatistics it is called a 'blip-down function'.

${ }^{8}$ Parametric sequential g-estimation assumes no interactions between the mediator and intermediate variables in the effect on the outcome. In sensitivity analysis testing this, only the (positive) interaction between self-efficacy and cognitive skill is significant, and the results of models including interactions with intermediate variables do not differ meaningfully.

${ }^{9}$ This approach does not rely on the assumption that errors are distributed normally. The resulting confidence intervals are therefore wider, and more accurate, than those calculated from traditional statistical approaches (Fox 2008).

${ }^{10}$ Analysis on the full sample, including those with imputed class destination, gives substantively similar results (available on request).

${ }^{11}$ Appendix Table $\mathrm{C} 1$ shows the imputed and non-imputed samples do not differ substantively on variables of interest.

${ }^{12}$ A full itemization of the scales and details of their construction is provided in appendix Table A1.

${ }^{13}$ Disability could be considered part of how class origin affects destination, but excluding it from the model does not substantively change estimates. 
${ }^{14}$ These coefficients for social-emotional skills' association with class destination can be compared to those in appendix Table $\mathrm{C} 2$, when the intermediate variables are not included in the regression. Without adjusting for cognitive skill and physical health, externalizing behavior has a larger, significant association with class destination, and self-esteem a smaller, less robust association.

${ }^{15}$ The lack of independent mediation effect found for internalizing behaviors could reflect the weakness of maternal reports of them for children at this age. As noted in appendix table A1, the scale for internalizing behaviors is less internally consistent than the scales for other measures of social-emotional skills. It should also be noted that internalizing behaviors in childhood are a robust predictor of subjective wellbeing in adulthood (Layard et al. 2014), while social mobility is not (Hadjar and Samuel 2015). 


\section{REFERENCES}

Acharya, Avidit, Matthew Blackwell, and Maya Sen. 2016. "Explaining Causal Findings Without Bias: Detecting and Assessing Direct Effects.” American Political Science Review 110(3):512-29.

Anger, Silke and Daniel D. Schnitzlein. 2016. "Cognitive Skills, Non-Cognitive Skills, and Family Background: Evidence from Sibling Correlations." Journal of Population Economics 30(2):591-620.

Bandura, Albert. 1986. Social Foundations of Thought and Action: A Social Cognitive Theory. Englewood Cliffs, NJ: Prentice-Hall.

Bandura, Albert, Claudio Barbaranelli, Gian Vittorio Caprara, and Concetta Pastorelli. 1996. "Multifaceted Impact of Self-Efficacy Beliefs on Academic Functioning." Child Development 67(3):1206-22.

Baumeister, Roy F., Jennifer D. Campbell, Joachim I. Krueger, and Kathleen D. Vohs. 2003. "Does High Self-Esteem Cause Better Performance, Interpersonal Success, Happiness, or Healthier Lifestyles?" Psychological Science in the Public Interest $4(1): 1-44$.

Beller, Emily. 2009. "Bringing Intergenerational Social Mobility Research into the Twenty-First Century: Why Mothers Matter.” American Sociological Review 74(4):507-28.

Beller, Emily and Michael Hout. 2006. "Intergenerational Social Mobility: The United States in Comparative Perspective." Future of Children 16:19-36.

Berezin, Mabel. 2010. "Emotions and the Economy." Pp. 109-30 in The Handbook of Economic Sociology, edited by N. J. Smelser and R. Swedberg. Princeton University Press. 
Bollen, Kenneth A. and Judea Pearl. 2013. "Eight Myths About Causality and Structural Equation Models.” Pp. 301-28 in Handbook of Causal Analysis for Social Research, edited by S. L. Morgan. Springer.

Bourdieu, Pierre. 2000. Pascalian Meditations. Stanford University Press.

Bourdieu, Pierre and Jean Claude Passeron. 1990. Reproduction in Education, Society and Culture. Sage Publications (CA).

Boyle, Gregory J. 2008. "Critique of the Five-Factor Model of Personality.” Pp. 295-312 in The Sage Handbook of Personality Theory and Assessment: Vol. 1 Personality Theories and Models, edited by G. J. Boyle, G. Matthews, and D. H. Saklofske. Sage Publications (CA).

Breen, Richard. 2005. "Foundations of Class Analysis in the Weberian Tradition." Pp. 31-50 in Approaches to Class Analysis, edited by E. O. Wright. Cambridge, UK: Cambridge University Press.

Buscha, Franz and Patrick Sturgis. 2017. "Declining Social Mobility? Evidence from Five Linked Censuses in England and Wales 1971-2011.” British Journal of Sociology in press.

Chan, Tak Wing and Vicki Boliver. 2013. "The Grandparents Effect in Social Mobility: Evidence from British Birth Cohort Studies.” American Sociological Review 78(4):662-78.

Cooley, Charles Horton. 1983. “The Self as Sentiment and Reflection.” Pp. 151-55 in Inside Social Life: Readings in Sociological Psychology and Microsociology, edited by S. . Cahill, K. Sandstrom, and C. Froyum. Oxford University Press.

Cunha, Flavio, James J. Heckman, and Susanne Schennach. 2010. "Estimating the 
Technology of Cognitive and Noncognitive Skill Formation.” Econometrica 78(3):883-931 .

Currie, Janet and Mark Stabile. 2006. "Child Mental Health and Human Capital Accumulation: The Case of ADHD.” Journal of Health Economics 25(6):10941118.

Daly, Michael, Liam Delaney, Mark Egan, and Roy F. Baumeister. 2015. "Childhood Self-Control and Unemployment Throughout the Life Span: Evidence From Two British Cohort Studies.” Psychological Science 26(6):709-23.

Deming, David J. 2015. “The Growing Importance of Social Skills in the Labor Market.” National Bureau of Economic Research (NBER). Working Paper (21473).

Demo, David H. and Ritch C. Savin-Williams. 1983. "Early Adolescent Self-Esteem as a Function of Social Class: Rosenberg and Pearlin Revisited.” American Journal of Sociology 88(4):763-74.

DiMaggio, Paul. 2012. "Sociological Perspectives on the Face-to-Face Enactment of Class Distinction.” Pp. 15-38 in Facing social class: How societal rank influences interaction., edited by S. T. Fiske and H. R. Markus. NY: Russell Sage Foundation.

Donnellan, M.Brent, Kali H. Trzesniewski, Richard W. Robins, Terrie E. Moffitt, and Avshalom Caspi. 2005. "Low Self-Esteem Is Related to Aggression, Antisocial Behavior, and Delinquency." Psychological Science 16(4):328-35.

Duckworth, Angela L. 2011. "The Significance of Self-Control.” Proceedings of the National Academy of Sciences of the United States of America 108(7):2639-40.

Duncan, Greg J. and Katherine Magnuson. 2011. "The Nature and Impact of Early Achievement Skills, Attention Skills, and Behavior Problems.” Pp. 47-69 in 
Whither Opportunity? Rising Inequality, Schools, and Children's Life Chances. New York: Russell Sage Foundation.

Duncan, Otis Dudley. 1966. "Path Analysis: Sociological Examples.” American Journal of Sociology 72(1):1-16.

Elander, James and Michael Rutter. 1996. "An Update on the Status of the Rutter Parents' and Teachers' Scales." Child and Adolescent Mental Health 1(1):31-35.

Elliott, Jane and Peter Shepherd. 2006. "Cohort Profile: 1970 British Birth Cohort (BCS70)." International Journal of Epidemiology 35(4):836-43.

England, Paula. 2015. "Sometimes the Social Becomes Personal: Gender, Class, and Sexualities." American Sociological Review 81(1):4-28.

Erikson, Robert and John H. Goldthorpe. 2002. "Intergenerational Inequality : A Sociological Perspective." Journal of Economic Perspectives 16(3):31-44.

Ermisch, John, Markus Jäntti, and Timothy M. Smeeding. 2012. "Socioeconomic Gradients in Children's Outcomes." Pp. 32-53 in From Parents to Children: The Intergenerational Transmission of Advantage, edited by J. Ermisch, M. Jäntti, and T. M. Smeeding. Russell Sage Foundation.

Falci, Christina D. 2011. "Self-Esteem and Mastery Trajectories in High School by Social Class and Gender." Social Science Research 40(2):586-601.

Farkas, George. 2003. "Cognitive Skills and Noncognitive Traits and Behaviors in Stratification Processes." Annual Review of Sociology 29(1):541-62.

Fletcher, Jason M. 2010. “Adolescent Depression and Educational Attainment: Results Using Sibling Fixed Effects." Health economics 19(7):855-71.

Fletcher, Jason M. and Barbara Wolfe. 2016. “The Importance of Family Income in the 
Formation and Evolution of Non-Cognitive Skills in Childhood." Economics of Education Review 54:143-54.

Fox, John. 2008. Applied Regression Analysis and Generalized Linear Models. Sage.

Gecas, Viktor. 1982. “The Self-Concept.” Annual Review of Sociology 8:1-33.

Goodman, Robert. 1997. "The Strengths and Difficulties Questionnaire: A Research Note." Journal of Child Psychology and Psychiatry 38(5):581-86.

Haas, Steven A. and Nathan Edward Fosse. 2008. "Health and the Educational Attainment of Adolescents: Evidence from the NLS97." Journal of Health and Social Behavior 49(June):178-92.

Hadjar, Andreas and Robin Samuel. 2015. "Does Upward Social Mobility Increase Life Satisfaction? A Longitudinal Analysis Using British and Swiss Panel Data.” Research in Social Stratification and Mobility 39:48-58.

Hauser, Robert M. 2002. Meritocracy, Cognitive Ability and the Sources of Occupational Success.

Heckman, James J., John Eric Humphries, and Tim Kautz. 2014. The Myth of Achievement Tests: The GED and the Role of Character in American Life. University of Chicago Press.

Heckman, James J., Rodrigo Pinto, and Peter Savelyev. 2013. "Understanding the Mechanisms Through Which an Influential Early Childhood Program Boosted Adult Outcomes.” The American Economic Review 103(6):2052-86.

Heckman, James J. and Yona Rubinstein. 2001. “The Importance of Noncognitive Skills: Lessons from the GED Testing Program.” American Economic Review 91(2):14549. 
Heckman, James J., Jora Stixrud, and Sergio Urzua. 2006. “The Effects of Cognitive and Noncognitive Abilities on Labor Market Outcomes and Social Behavior." Journal of Labor Economics 24(3):411-82.

Hitlin, Steven and Monica Kirkpatrick Johnson. 2015. "Reconceptualizing Agency within the Life Course: The Power of Looking Ahead.” American Journal of Sociology 120(5):1429-72.

Hochschild, Arlie Russell. 1979. "Emotion Work, Feeling Rules and Social Structure.” American Journal of Sociology 85(3):551-75.

Honaker, James, Gary King, and Matthew Blackwell. 2011. “AMELIA II: A Program for Missing Data." Journal Of Statistical Software 45(7):1-54.

Hout, M. 2014. "A Summary of What We Know about Social Mobility." The ANNALS of the American Academy of Political and Social Science 657(1):27-36.

Hsin, Amy and Yu Xie. 2017. "Life Course Changes in the Mediation of Cognitive and Non-Cognitive Skills for Parental Effects on Children's Academic Achievement.” Social Science Research 63(March):150-65.

Illouz, Eva, Daniel Gilon, and Mattan Shachak. 2014. "Emotions and Cultural Theory." Pp. 221-44 in Handbook of the Sociology of Emotions, Vol. II, edited by J. E. Stets and J. H. Turner. Springer.

Imai, Kosuke, Luke Keele, and Teppei Yamamoto. 2010. "Identification, Inference and Sensitivity Analysis for Causal Mediation Effects.” Statistical Science 25(1):51-71. Jackson, M., R. Erikson, J. H. Goldthorpe, and M. Yaish. 2007. "Primary and Secondary Effects in Class Differentials in Educational Attainment: The Transition to A-Level Courses in England and Wales.” Acta Sociologica 50(3):211-29. 
James, Spencer L. and Paul R. Amato. 2013. "Self-Esteem and the Reproduction of Social Class.” Social science quarterly 94(4):933-55.

Jencks, Christopher. 1979. Who Gets Ahead?: The Determinants of Economic Success in America. Basic Books.

Johnston, David W., Stefanie Schurer, and Michael A. Shields. 2013. "Exploring the Intergenerational Persistence of Mental Health: Evidence from Three Generations.” Journal of health economics 32(6):1077-89.

Kao, Grace and Jennifer S. Thompson. 2003. "Racial and Ethnic Stratification in Educational Achievement and Attainment." Annual Review of Sociology 29(1):41742.

Kearney, Melissa S. 2006. "Intergenerational Mobility for Women and Minorities in the United States." The Future of children / Center for the Future of Children, the David and Lucile Packard Foundation 16(2):37-53.

Kemper, Theodore D. 2006. "Status, Power and the Power-Status Theory of Emotions." Pp. 87-113 in Handbook of the Sociology of Emotions, edited by J. . E. Stets and J. H. Turner. Springer.

Kraus, Michael W. and Dacher Keltner. 2009. "Signs of Socioeconomic Status: A ThinSlicing Approach.” Psychological Science 20(1):99-106.

Kraus, Michael W., Paul K. Piff, and Dacher Keltner. 2009. "Social Class, Sense of Control, and Social Explanation." Journal of personality and social psychology 97(6):992-1004.

Lareau, Annette. 2002. "Invisible Inequality: Social Class and Childrearing in Black Families and White Families." American Sociological Review 67:747-76. 
Lareau, Annette. 2003. Unequal Childhoods: Class, Race, and Family Life. University of California Press.

Lawrence, D. 1981. “The Development of a Self-Esteem Questionnaire.” British Journal of Educational Psychology 51(2):245-51.

Layard, Richard, Andrew E. Clark, Francesca Cornaglia, Nattavudh Powdthavee, and James Vernoit. 2014. "What Predicts a Successful Life? A Life-Course Model of Well-Being." The Economic Journal 124(580):F720-38.

Lizardo, Omar. 2017. “Improving Cultural Analysis.” American Sociological Review 82(1):88-115.

Maralani, Vida and S. Choi. n.d. Cohort Trends in the Relationship between NonCognitive Skills and Educational Attainment.

Mazumder, Bhashkar. 2015. "Inequality in Skills and the Great Gatsby Curve." Essays on Issues: The Federal Reserve Bank of Chicago Number 330.

McLanahan, Sara and Christine Percheski. 2008. "Family Structure and the Reproduction of Inequalities.” Annual Review of Sociology 34(1):257-76.

McLaughlin, Katie A. et al. 2011. "Childhood Socio-Economic Status and the Onset, Persistence, and Severity of DSM-IV Mental Disorders in a US National Sample.” Social Science \& Medicine 73(7):1088-96.

McLeod, Jane D. 2013. “Social Stratification and Inequality.” Pp. 229-54 in Handbook of Sociology of Mental Health, edited by C. S. Aneshensel, J. C. Phelan, and A. Bierman. Springer.

McLeod, Jane D. and Karen Kaiser. 2004. "Childhood Emotional and Behavioral Problems and Educational Attainment." American Sociological Review 69(5):636- 
58.

McLeod, Jane D., Ryotaro Uemura, and Shawna Rohrman. 2012. “Adolescent Mental Health, Behavior Problems, and Academic Achievement." Journal of Health and Social Behavior 53(4):482-97.

Mead, George Herbert. 1983. “The Self as Social Structure.” Pp. 156-60 in Inside Social Life: Readings in Sociological Psychology and Microsociology, edited by S. E. Cahill, K. Sandstrom, and C. Froyum. Oxford University Press.

Mensah, Fiona K. and Kathleen E. Kiernan. 2010. “Parents’ Mental Health and Children's Cognitive and Social Development: Families in England in the Millennium Cohort Study." Social psychiatry and psychiatric epidemiology 45(11):1023-35.

Moffitt, Terrie E. et al. 2011. “A Gradient of Childhood Self-Control Predicts Health, Wealth, and Public Safety." Proceedings of the National Academy of Sciences of the United States of America 108(7):2693-98.

Mood, C., JO. Jonsson, and E. Bihagen. 2012. "Socioeconomic Persistence across Generations: The Role of Cognitive and Non-Cognitive Processes." in From Parents to Children: The Intergenerational Transmission of Advantage, edited by J. F. Ermisch, M. Jäntti, and T. M. Smeeding. New York: Russell Sage Foundation.

Mostafa, Tarek and Richard D. Wiggins. 2014. "Handling Attrition and Non-Response in the 1970 British Cohort Study." Center for Longitudinal Studies Working Paper, Institute of Education, University of London 2(June).

Nowicki, Stephen and Bonnie R. Strickland. 1973. “A Locus of Control Scale for Children.” Journal of Consulting and Clinical Psychology 40(1):148-54. 
Protsch, Paula and Heike Solga. 2015. "How Employers Use Signals of Cognitive and Noncognitive Skills at Labour Market Entry. Insights from Field Experiments.” European Sociological Review 31(532):521-25.

Ridgeway, Cecilia L. 2014. "Why Status Matters for Inequality." American Journal of Sociology 79(1):1-16.

Robins, James M. 1989. "The Control of Confounding By Intermediate Variables.” Statistics in Medicine 8:679-701.

Robins, James M. 1999. “Association, Causation, And Marginal Structural Models.” Synthese 121(1/2):151-79.

Rosenbaum, Paul R. 1984. "The Consequences of Adjustment for a Concomitant Variable That Has Been Affected by Treatment." Journal of the Royal Statistical Society. Series A: General 147(5):656-66.

Rosenberg, Morris and Leonard I. Pearlin. 1978. "Social Class and Self-Esteem Among Children and Adults.” American Journal of Sociology 84(1):53-77.

Ross, Catherine E. and John Mirowsky. 2012. "The Sense of Personal Control: Social Structural Causes and Emotional Consequences.” Pp. 379-404 in Handbook of Sociology of Mental Health, edited by C. S. Aneshensel, J. C. Phelan, and A. Bierman. New York: Springer.

Rutter, Michael. 1967. “A Children’s Behaviour Questionnaire For Completion By Teachers: Preliminary Findings." Journal of Child Psychology and Psychiatry $8(1): 1-11$.

Sampson, Robert J. 2016. “The Characterological Imperative: On Heckman, Humphries, and Kautz's The Myth of Achievement Tests: The GED and the Role of Character." 
Journal of Economic Literature 54(2):1-21.

Savelyev, Peter. 2014. "Psychological Skills, Education, and Longevity of High-Ability Individuals." Unpublished manuscript, Vanderbuilt University, Department of Economics.

Schwenkenberg, Julia M. 2014. "Occupations and the Evolution of Gender Differences in Intergenerational Socioeconomic Mobility.” Economics Letters 124(3):348-52.

Sennett, Richard and Jonathan Cobb. 1993. The Hidden Injuries of Class. London: Faber \& Faber.

Sewell, William H. and Robert M. Hauser. 1974. Education, Occupation, and Earnings. Achievement in the Early Career. New York: Academic Press Inc.

Shariff, Azim F., Jessica L. Tracy, and Jeffrey L. Markusoff. 2012. “(Implicitly) Judging a Book by Its Cover: The Power of Pride and Shame Expressions in Shaping Judgments of Social Status.” Personality \& Social Psychology Bulletin 38(9):117893.

Simon, Robin W. 2014. "Mental Health and Emotions." Pp. 429-51 in Handbook of the Sociology of Emotions, edited by J. E. Stets and J. H. Turner. Springer.

Skeggs, Beverley. 2004. Class, Self, Culture. Routledge.

The Brookings Institute. 2014. “Essays on Character and Opportunity.” Retrieved November 15, 2014 (http://www.brookings.edu/about/centers/ccf/characteropportunity-project).

Turney, Kristin and Sara McLanahan. 2015. “The Academic Consequences of Early Childhood Problem Behaviors.” Social Science Research 54:131-45. VanderWeele, Tyler J. 2015. Explanation in Causal Inference: Methods for Mediation 
and Interaction. Oxford University Press.

VanderWeele, Tyler J. and Stijn Vansteelandt. 2009. “Conceptual Issues Concerning Mediation, Interventions and Composition." Statistics and Its Interface 2:457-68.

Vansteelandt, Stijn and Marshall Joffe. 2014. "Structural Nested Models and GEstimation: The Partially Realized Promise.” Statistical Science 29(4):707-31.

Wharton, Amy S. 2009. “The Sociology of Emotional Labor.” Annual Review of Sociology 35(1):147-65.

Wheaton, B. 1980. "The Sociogenesis of Psychological Disorder: An Attributional Theory." Journal of Health and Social Behavior 21(2):100-124.

Wodtke, Geoffrey T. 2017. "Social Relations, Technical Divisions, and Class Stratification in the United States: An Empirical Test of the Death and Decomposition of Class Hypotheses.” Social Forces 95(4):1479-1508.

Yeung, K. T. and J. L. Martin. 2003. "The Looking Glass Self: An Empirical Test and Elaboration.” Social Forces 81(3):843-79.

Zelizer, Viviana A. 2012. "How I Became a Relational Economic Sociologist and What Does That Mean?" Politics and Society 47(2006):1-31. 


\section{TABLES}

Table 1: Descriptive Statistics

\begin{tabular}{lcccccc}
\hline Statistic & Mean & St. Dev. & Min & Pctl(25) & Pctl(75) & Max \\
\hline Class Measures: & & & & & & \\
$\quad$ Destination Class & 4.23 & 1.20 & 1 & 3 & 5 & 6 \\
$\quad$ Origin Class & 3.52 & 1.35 & 1 & 3 & 5 & 6 \\
Mediators: & & & & & & \\
$\quad$ Low Self-Control & 17.15 & 4.51 & 1.26 & 13.60 & 20.35 & 38.53 \\
$\quad$ Externalizing Behaviors & 2.41 & 3.27 & -9.46 & 0.00 & 4.00 & 24.00 \\
$\quad$ Internalizing Behaviors & 2.22 & 2.20 & -5.55 & 0.58 & 3.04 & 16.00 \\
$\quad$ Low Self-Esteem & 3.90 & 2.39 & -5.55 & 2.00 & 5.50 & 12.99 \\
$\quad$ Low Self-Efficacy & 5.21 & 2.00 & -1.54 & 3.91 & 6.50 & 12.53 \\
Baseline Covariates: & & & & & & \\
$\quad$ Female & .49 & .50 & 0 & 0 & 1 & 1 \\
$\quad$ Racial/Ethnic Minority & .07 & .26 & 0 & 0 & 0 & 1 \\
$\quad$ Child Disability & .04 & .20 & 0 & 0 & 0 & 1 \\
Intermediate Covariates: & & & & & & \\
$\quad$ Cognitive Ability & 0.07 & 0.74 & -3.16 & -0.43 & 0.57 & 2.72 \\
$\quad$ Poor Health & 0.41 & 0.82 & -2.81 & 0.00 & 0.73 & 4.00 \\
\hline
\end{tabular}

Note: a. Statistics averaged across five multiply imputed datasets.

b. For comparison with non-imputed sample, see appendix table A2

Table 2: Sequential g-estimates for the mediation of the intergenerational class association through socialemotional skills

\begin{tabular}{|c|c|c|c|c|c|c|}
\hline Mediator & $\mathrm{ACDE}^{\mathrm{a}}$ & Mediated (ppt.) & Mediated (pc.) & S.E. ${ }^{b}$ & Lower Bound & Upper Bound \\
\hline Males and Females: & & & & & & \\
\hline Baseline Association & 0.219 & & & 0.008 & 0.211 & 0.227 \\
\hline -All Socio-Emotional Skills & 0.185 & 0.034 & 0.153 & 0.008 & 0.177 & 0.194 \\
\hline -Self-Concept & 0.201 & 0.018 & 0.081 & 0.008 & 0.193 & 0.209 \\
\hline -Behaviors & 0.197 & 0.021 & 0.098 & 0.008 & 0.189 & 0.206 \\
\hline Males Only: & & & & & & \\
\hline Baseline Association & 0.247 & & & 0.012 & 0.235 & 0.259 \\
\hline -All Socio-Emotional Skills & 0.209 & 0.038 & 0.155 & 0.012 & 0.197 & 0.221 \\
\hline -Self-Concept & 0.215 & 0.033 & 0.132 & 0.012 & 0.202 & 0.227 \\
\hline -Behaviors & 0.218 & 0.029 & 0.117 & 0.012 & 0.207 & 0.230 \\
\hline Females Only: & & & & & & \\
\hline Baseline Association & 0.188 & & & 0.011 & 0.176 & 0.199 \\
\hline -All Socio-Emotional Skills & 0.156 & 0.031 & 0.167 & 0.013 & 0.143 & 0.169 \\
\hline -Self-Concept & 0.157 & 0.030 & 0.160 & 0.012 & 0.146 & 0.169 \\
\hline -Behaviors & 0.172 & 0.016 & 0.083 & 0.013 & 0.159 & 0.185 \\
\hline
\end{tabular}

Note: a. ACDE is the average controlled direct effect, or the intergenerational class association conditional on mediators, intermediate and baseline variables, as in text.b. Standard errors (S.E.s) are bootstrapped. 
Table 3: First stage estimates from the sequential g-estimation

\begin{tabular}{|c|c|c|c|}
\hline & \multicolumn{3}{|c|}{ Dependent Variable: Class Destination } \\
\hline & Self-Concept & Behavioral & All \\
\hline & $(1)$ & $(2)$ & $(3)$ \\
\hline Low Self-Efficacy & $-0.128^{* * *}$ & & $-0.101^{* *}$ \\
\hline Low Self-Esteem & $-0.113^{* * *}$ & & $-0.089^{* *}$ \\
\hline Low Self-Esteem * Low Self-Efficacy & 0.007 & & 0.008 \\
\hline Class Origin $*$ Low Self-Efficacy & 0.003 & & -0.0001 \\
\hline Class Origin * Low Self-Esteem & 0.017 & & 0.016 \\
\hline Low Self-Control & & $-0.204^{* * *}$ & $-0.173^{* * *}$ \\
\hline Externalizing Behaviors & & -0.060 & -0.041 \\
\hline Internalizing Behaviors & & -0.019 & -0.014 \\
\hline Low Self-Control * Externalizing Behaviors & & 0.008 & 0.009 \\
\hline Low Self-Control * Internalizing Behaviors & & -0.011 & -0.016 \\
\hline Externalizing * Internalizing Behaviors & & 0.0003 & -0.001 \\
\hline Class Origin * Low Self-Control & & 0.012 & 0.009 \\
\hline Class Origin * Externalizing Behaviors & & -0.002 & -0.004 \\
\hline Class Origin * Internalizing Behaviors & & 0.002 & 0.002 \\
\hline Low Self-Control * Low Self-Efficacy & & & -0.015 \\
\hline Low Self-Control * Low Self-Esteem & & & 0.015 \\
\hline Externalizing Behaviors * Low Self-Efficacy & & & -0.008 \\
\hline Externalizing Behaviors ${ }^{*}$ Low Self-Esteem & & & -0.004 \\
\hline Internalizing Behaviors * Low Self-Efficacy & & & 0.015 \\
\hline Internalizing Behaviors * Low Self-Esteem & & & -0.007 \\
\hline Cognitive Skill & $0.345^{* * *}$ & $0.322^{* * *}$ & $0.288^{* * *}$ \\
\hline Poor Health & $-0.030^{* *}$ & -0.006 & -0.006 \\
\hline Class Origin & $0.123^{* * *}$ & $0.125^{* * *}$ & $0.121^{* * *}$ \\
\hline Female & $0.136^{* * *}$ & 0.038 & $0.058^{* *}$ \\
\hline Racial/Ethnic Minority & $0.370^{* * *}$ & $0.362^{* * *}$ & $0.369^{* * *}$ \\
\hline Disability & 0.012 & -0.008 & 0.003 \\
\hline Constant & $3.637^{* * *}$ & $3.670^{* * *}$ & $3.676^{* * *}$ \\
\hline$N$ & 11,020 & 11,020 & 11,020 \\
\hline $\mathrm{R}^{2}$ & 0.169 & 0.174 & 0.182 \\
\hline Residual Std. Error & $1.098(\mathrm{df}=11008)$ & $1.095(\mathrm{df}=11004)$ & $1.090(\mathrm{df}=10993)$ \\
\hline
\end{tabular}

Note: ${ }^{*} \mathrm{p}<.05 ;{ }^{* *} \mathrm{p}<.01 ;{ }^{* * *} \mathrm{p}<.001$ 


\section{FIGURES}

Figure 1. Social-Emotional Skills by Measure and Class Origin

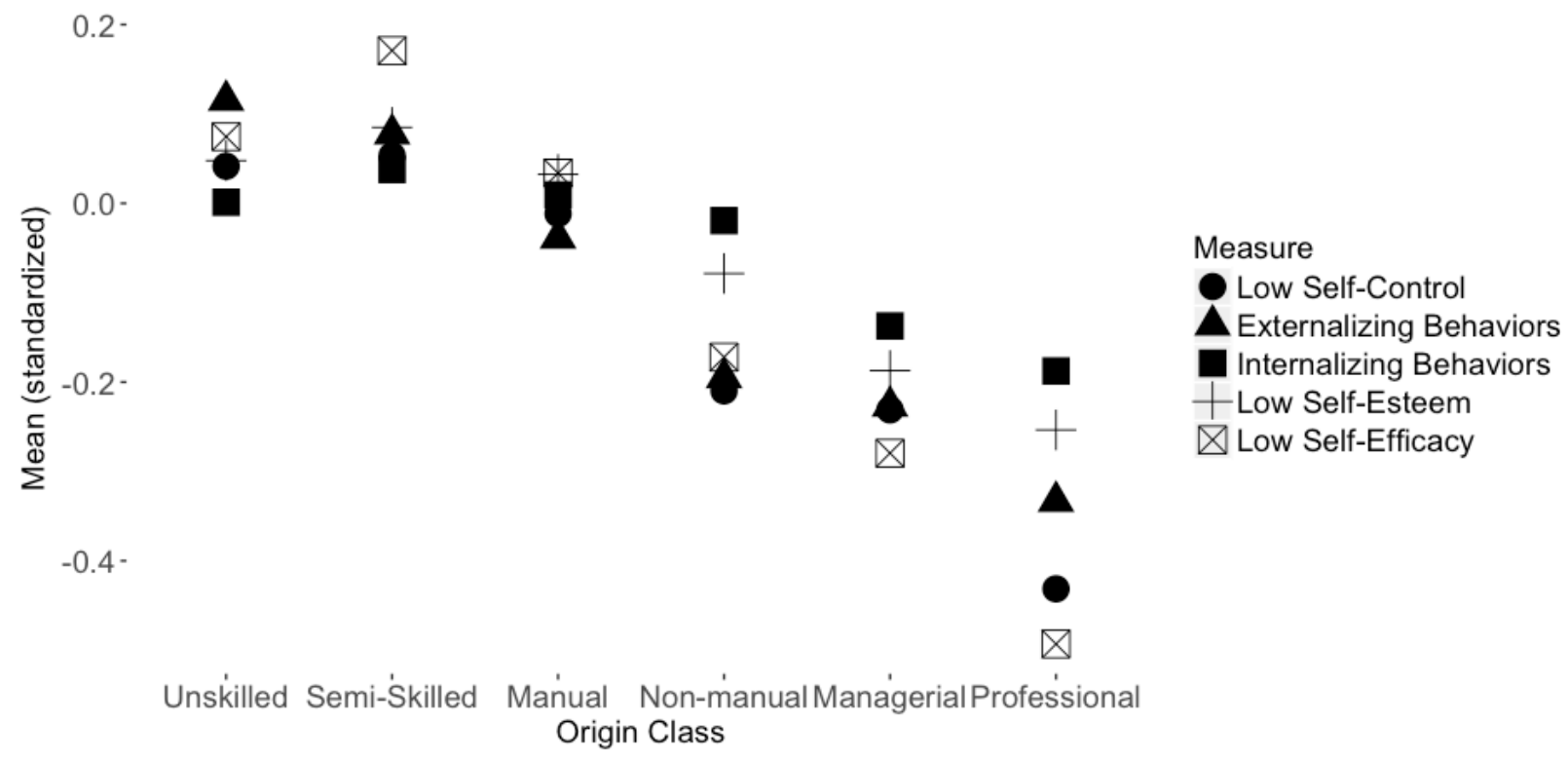

Figure 2. Sequential G-estimates of the Mediation of the Intergenerational Class Association by Social-Emotional Skills

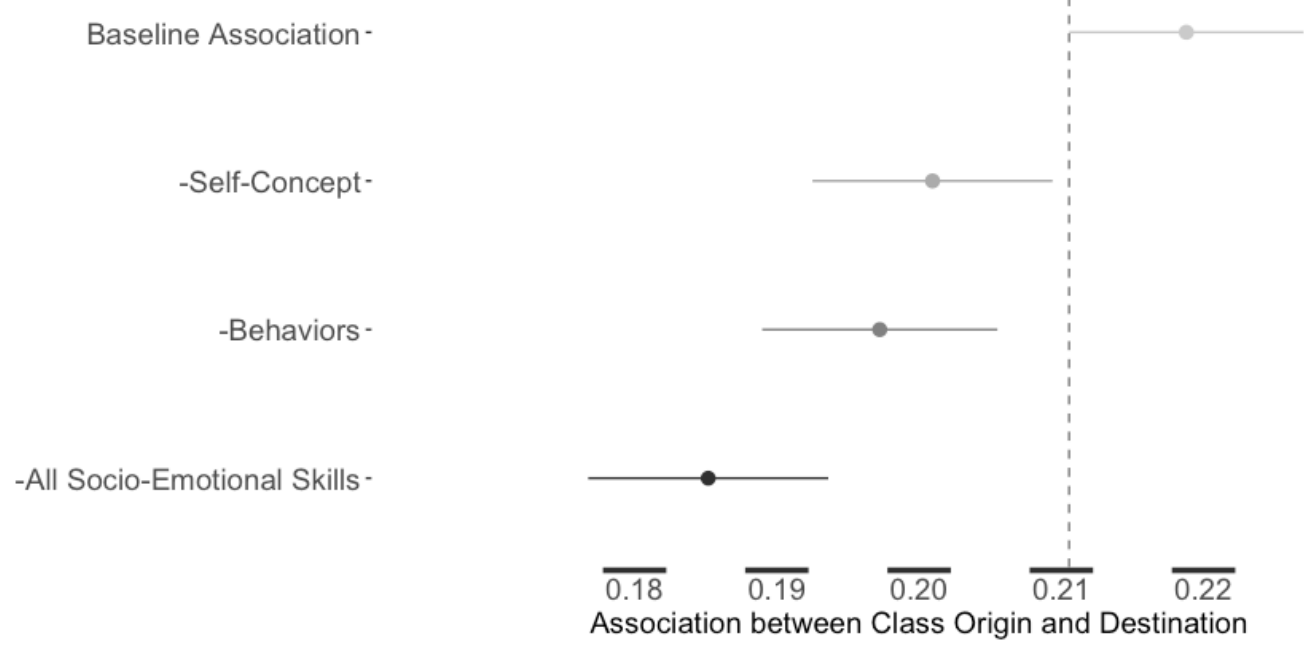




\section{APPENDIX A: Measures of Child Social-Emotional Skills}

Table A1: Measures of Social-Emotional Skills

\section{Behaviors}

\section{Self-Control}

Reporter

Cronbach's

alpha

Item Scale

Teacher

0.91 (9 items)

1-47 visual scale (divided by 20 for comparability)

Items

Child is
daydreaming
Cannot concentr
on particular task
Becomes bored
during class

Shows perseverance (R)

Easily distracted

Pays attention in class (R)

Forgetful on complex tasks

Completes tasks (R)

Fails to finish tasks

$\begin{array}{ll}\text { Externalizing } & \text { Internalizing } \\ \text { Mother } & \text { Mother } \\ 0.77 \text { (13 items) } & 0.52 \text { (13 items) } \\ \text { Does Not Apply (0), Somewhat applies } \\ \text { (1), Certainly Applies (2). }\end{array}$

Very restless. Often running about or jumping up and down

Is squirmy or fidgety

Often destroys own or others' belongings

Frequently fights other children

Not much liked by other children

Irritable. Is quick to fly off the handle

Sometimes takes things belonging to others

Has twitches, mannerisms or tics of the face or body

Is often disobedient
Often worried, worries about many things

Tends to do things on his/her own rather solitary

Often appears miserable, unhappy, tearful or distressed

Tends to be fearful things or new situations

Frequently sucks thumb or finger

Frequently bites nails or fingers

Fussy or overparticular

Tears on arrival at school

Has sleeping difficulty or afraid of new
Self-Concept

Self-Esteem

Self-Efficacy

Child

Child

0.70 (13 items)

0.53 (13 items)

No (0), Don't

Know (0.5), Yes (1)

No (0), Don't Know (0.5), Yes (1)

Most of the time it is not worth trying hard because things never turn out right anyway

Often feel lonely at school

Wishing can make good things happen

Others fall out with you

People good to you no matter how you act toward them

Like team games

It's almost useless to try in school

Others say nasty things about you

A high mark is a matter of luck for you

Often blamed for

Feel shy in front of teacher things that aren't your fault

Feel sad because no-one to play with

The kind of person who believes planning ahead makes things turn out well (R)

Lots of things about self would change

Find it easy to get up in the morning (R)

Feel foolish/uneasy speaking to teacher
When bad things to you, it is usually someone else's fault 


\begin{tabular}{|c|c|c|c|}
\hline $\begin{array}{l}\text { Cannot settle to } \\
\text { anything for } \\
\text { more than a few } \\
\text { moments. }\end{array}$ & $\begin{array}{l}\text { Has eating or } \\
\text { appetite problems }\end{array}$ & $\begin{array}{l}\text { Feel foolish in } \\
\text { front of peers }\end{array}$ & $\begin{array}{l}\text { If someone is very } \\
\text { angry with you, it } \\
\text { is impossible to } \\
\text { make friends again }\end{array}$ \\
\hline $\begin{array}{l}\text { Has temper } \\
\text { tantrums }\end{array}$ & Wets bed at night & $\begin{array}{l}\text { Feel foolish } \\
\text { talking to parents }\end{array}$ & $\begin{array}{l}\text { When nice things } \\
\text { happen to you it is } \\
\text { only good luck }\end{array}$ \\
\hline Often tells lies & Wets self in day & $\begin{array}{l}\text { Often have to find } \\
\text { new friends }\end{array}$ & $\begin{array}{l}\text { When you get into } \\
\text { an argument, it is } \\
\text { usually the other } \\
\text { person's fault }\end{array}$ \\
\hline $\begin{array}{l}\text { Bullies other } \\
\text { children }\end{array}$ & Soils self in day & $\begin{array}{l}\text { Others think you } \\
\text { tell lies }\end{array}$ & $\begin{array}{l}\text { Studying for tests } \\
\text { is waste of time }\end{array}$ \\
\hline
\end{tabular}

Note: 'R' denotes the item was reverse-coded for scale consistency. 


\section{APPENDIX B: Directed Acyclic Graph (DAG) of Analytical Strategy}

Figure B1: Directed Acyclic Graph (DAG) of Analytical Strategy

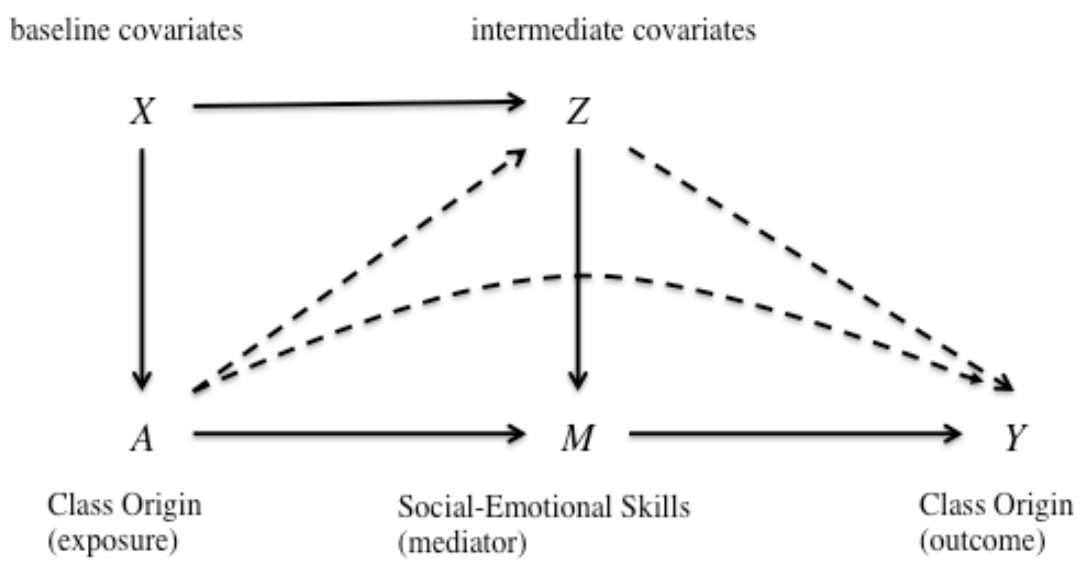

Note: Dashed lines represent the controlled direct effect (CDE) of class origins on class destination not through social-emotional skills. Unobserved errors are omitted. 


\section{APPENDIX C: Supplemental Tables}

Table C1: Comparison of analysis (imputed) and full (non-imputed) sample characteristics

\begin{tabular}{lcccc}
\hline \hline Statistic & Mean, Full & S.D., Full & Mean, Analysis & S.D., Analysis \\
Class Measures: & & & & \\
$\quad$ Destination Class & 4.24 & 1.19 & 4.23 & 1.20 \\
$\quad$ Origin Class & 3.69 & 1.22 & 3.52 & 1.35 \\
Mediators: & & & & \\
$\quad$ Low Self-Control & 12.96 & 4.47 & 17.15 & 4.51 \\
Externalizing Behaviors & 2.26 & 3.09 & 2.41 & 3.27 \\
Internalizing Behaviors & 2.19 & 2.17 & 2.22 & 2.20 \\
Low Self-Esteem & 3.88 & 2.41 & 3.91 & 2.40 \\
$\quad$ Low Self-Efficacy & 5.17 & 1.99 & 5.21 & 2.00 \\
Baseline Covariates: & & & & \\
$\quad$ Female & 0.49 & 0.50 & 0.49 & 0.50 \\
$\quad$ Racial/Ethnic Minority & 0.06 & 0.24 & 0.07 & 0.26 \\
Child Disability & 0.05 & 0.21 & 0.04 & 0.20 \\
Intermediate Covariates: & & & & \\
$\quad$ Cognitive Ability & 0.09 & 0.72 & 0.07 & 0.74 \\
Poor Health & 0.39 & 0.80 & 0.41 & 0.82 \\
\hline
\end{tabular}

Note: S.D.=standard deviation.

Statistics for imputed sample are averaged across five multiply imputed datasets. 


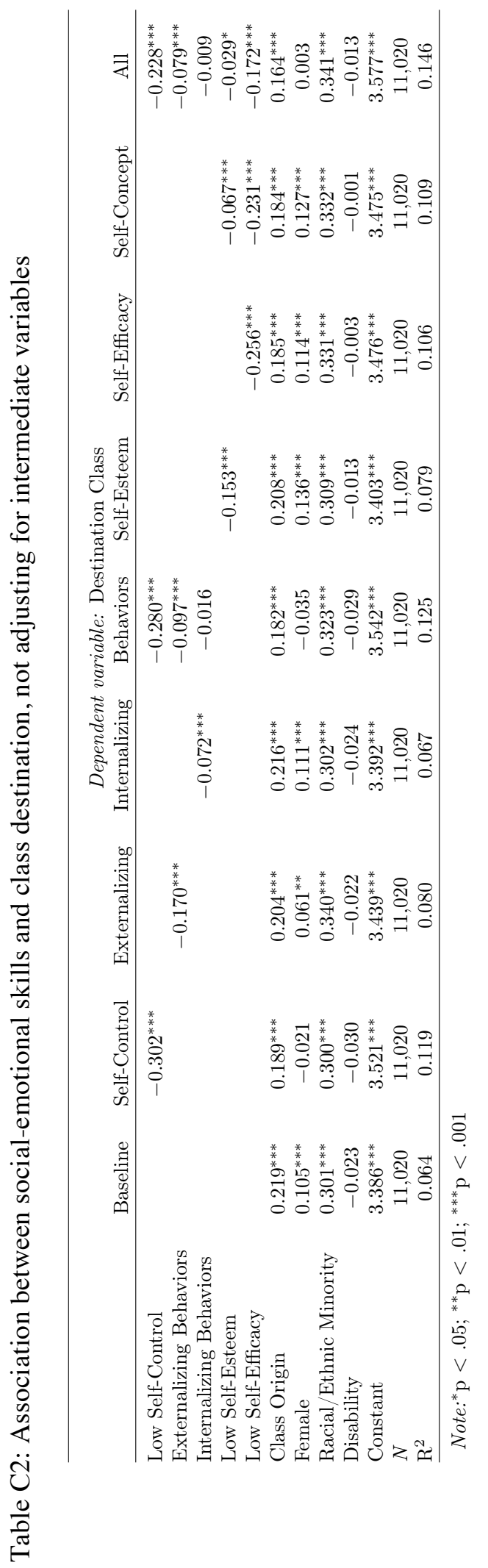


Table C3: Sequential g-estimates of the mediation effect of social-emotional skills, not adjusting for concurrent cognitive ability

\begin{tabular}{|c|c|c|c|c|c|c|}
\hline Mediator & $\mathrm{ACDE}^{\mathrm{a}}$ & Mediated (ppt.) & Mediated (pc.) & S.E. ${ }^{b}$ & Lower Bound & Upper Bound \\
\hline Males and Females: & & & & & & \\
\hline Baseline Association & 0.219 & & & 0.008 & 0.211 & 0.227 \\
\hline -All Socio-Emotional Skills & 0.166 & 0.053 & 0.241 & 0.008 & 0.158 & 0.174 \\
\hline -Self-Concept & 0.186 & 0.033 & 0.151 & 0.008 & 0.177 & 0.194 \\
\hline -Behaviors & 0.183 & 0.036 & 0.163 & 0.008 & 0.175 & 0.191 \\
\hline Males Only: & & & & & & \\
\hline Baseline Association & 0.247 & & & 0.012 & 0.235 & 0.259 \\
\hline -All Socio-Emotional Skills & 0.189 & 0.058 & 0.234 & 0.013 & 0.177 & 0.202 \\
\hline -Self-Concept & 0.195 & 0.052 & 0.212 & 0.021 & 0.174 & 0.216 \\
\hline -Behaviors & 0.204 & 0.044 & 0.177 & 0.012 & 0.192 & 0.215 \\
\hline Females Only: & & & & & & \\
\hline Baseline Association & 0.188 & & & 0.011 & 0.176 & 0.199 \\
\hline -All Socio-Emotional Skills & 0.121 & 0.066 & 0.354 & 0.019 & 0.103 & 0.140 \\
\hline -Self-Concept & 0.148 & 0.039 & 0.209 & 0.018 & 0.130 & 0.166 \\
\hline -Behaviors & 0.159 & 0.028 & 0.151 & 0.013 & 0.146 & 0.172 \\
\hline
\end{tabular}

Note: a. ACDE is the average controlled direct effect, or the intergenerational class association conditional on mediators, intermediate and baseline variables, as in text. b. Standard errors (S.E.s) are bootstrapped. 